\title{
Real-Time Approach for Demand Response Tariffs Definition Using Decision Trees
}

\author{
Cátia Silva, Pedro Faria, Zita Vale \\ Polytechnic of Porto \\ Porto, Portugal \\ cvcds@isep.ipp.pt; pnf@isep.ipp.pt; zav@isep.ipp.pt
}

\begin{abstract}
Giving the small resources more information about the transactions in the market will have a great influence on the balance and increase the uncertainty. Business models that are prepared to deal with small consumers and/or with small Distributed Generation units need to emerge to deal with this problem. The authors present a methodology able to minimize the operation costs for the Aggregator of these small resources but also find a fair remuneration according to their participation in the management of the local grid. The methodology could be explored by two approaches depending on time horizon: planning or operation. In the present paper, the two will be compared showing the viability of the path selected by the authors for the real-time approach - assign a remuneration group to a consumer considering the actual participation and the rules provided by a classification method.
\end{abstract}

Index Terms - Aggregation, Business Model, Classification, Demand Response, Decision Trees

\begin{tabular}{|c|c|}
\hline & NOMENCLATURE \\
\hline$c$ & Number of consumers $(c=1,2, \ldots, C)$ \\
\hline$C$ & Maximum number of consumers $\mathrm{c}$ \\
\hline$C_{D G}(p)$ & Distributed generation unit $\mathrm{p}$ cost \\
\hline$C_{I D R}(c)$ & $\begin{array}{l}\text { Incentive based Demand Response cost for } \\
\text { consumer c }\end{array}$ \\
\hline$C_{N S P}$ & Non-supplied power cost \\
\hline$C_{\text {Supa }}($ sa $)$ & Regular sa supplier cost \\
\hline$C_{\text {Supr }}(s r)$ & Additional sr supplier cost \\
\hline$p$ & Each generator $(p=1,2, \ldots, \mathrm{P})$ \\
\hline$P$ & Number of producers $\mathrm{p}$ \\
\hline $\mathrm{P}^{\text {add }}$ Supllier $(s a)$ & Power schedule for additional supplier \\
\hline$P^{\text {add Max }}$ Supllier $(s a)$ & Maximum power of additional supplier \\
\hline$P^{\text {addTotal }}$ Supllier $(s a)$ & $\begin{array}{l}\text { Maximum total power of all additional } \\
\text { suppliers }\end{array}$ \\
\hline $\mathrm{P}_{\mathrm{DG}}(p)$ & $\begin{array}{l}\text { Scheduled power for Distributed Generation } \\
\text { unit } p\end{array}$ \\
\hline $\operatorname{PDR}(c)$ & $\begin{array}{l}\text { Scheduled power reduction Demand } \\
\text { Response program for consumer } c\end{array}$ \\
\hline$P^{\text {Initial }}$ Load $(c)$ & Initial consumption of the consumers \\
\hline
\end{tabular}

The present work was done and funded in the scope of the following projects: MAS-Socety Project, CEECIND/02887/2017, SFRH/BD/144200/2019, and UID/EEA/00760/2019 funded by FEDER Funds through COMPETE program and by National Funds through FCT.

$$
\begin{aligned}
& P_{D G^{M a x}} \\
& \mathrm{P}_{\mathrm{NSP}} \\
& P^{r e g} \text { Max } \text { Supllier (sr) } \\
& P^{\text {reg Total }} \text { Supllier }(s r) \\
& P^{\text {reg }} \text { Supllier }(s r) \\
& P^{\text {TotalMax }} D G \\
& S \\
& \text { sa } \\
& s r
\end{aligned}
$$

\section{INTRODUCTION}

The policies and strategies for the management of Energy Market should attend the trends of the revolution brought by the concept of Smart Grids, namely with the inclusion consumers through Demand Response (DR) [1], [2]. Considering the importance of environmental objectives, that should be achieved, renewable energies are starting to be a very clear option to replace fossil fuels in the context of energy generation. Thus, the organization of the sector rethought. The physical balance between production and consumption in real time is a key problem for network operators due to the economic impossibility of large-scale storage. The existing Distributed Generation (DG) panoply, namely renewable based energy, and DR may be a valuable aid in the so-called "Money energy" problem. This problem is defined by the "energy only" markets where a deficit of investment in peaking units exists caused by lack of revenue [3].

The flexibility provided by DR to system operators, e.g. through shifting consumption across the day or changing the consumption level per period, can be useful when applied, for example, to small consumers. This can have impact in an Aggregator, namely, Virtual Power Players (VPP) [4]. With VPP, small resources will be able to have a more direct impact in the energy market. Small consumers (domestic and tertiary), DG units, prosumers and systems stores can be associated with this entity. The goal is to find the balance on a local level avoiding several problems namely transport losses. 
As mention, the Energy market needs to follow the trends and, consequently, the actual Business Models should be updated [5]. Introducing these small resources must exist a way to compensate for the discomfort caused by their participation in the management of the local market. In fact, the VPP, in addition, to focus on minimization of the operation costs should also find a solution with a fair remuneration - according to the actual participation. The authors developed an approach for VPP considering all the referred points. The methodology proposed in the present paper has five different phases:

- Profiling - filter and select important data from resources;

- Scheduling - optimization method applied to find the minimization of the operation costs;

- Aggregation - group the resources according to their participation in the management of the local market;

- Remuneration - compensate considering the groups and incentivize to continuous participation;

- Classification - creating rules for a real-time approach.

Being considered the development of previous works in the same area by the authors [6], in the present paper, the Classification phase will be performed to prove the viability. For a real-time approach, the authors considered only two phases, since the time horizon smaller: Scheduling and Classification. For a training phase, all the five phases should be completed (planning approach), and the output shows the remuneration groups and a decision tree. Having this, a reschedule is done and the rules provided will attribute a remuneration group for each resource. The study in this paper will consider the possibility of including new resources in the operation approach.

After this section, Section 2 includes the the proposed methodology. In Section 3 and 4, the case study and the results are presented, respectively. Section 5 summarizes the findings.

\section{APPROACH}

As mention in the Introduction, the proposed methodology has the main goal to introduce small consumers into the transactions of the energy market in an optimal way, managing all the resources from the Aggregator. Fig.1 presents the four main steps proposed by the authors. Fig. 1 is divided into two different situations: planning (black path) or operation (red path). The authors were able to give enough flexibility to the methodology to function in different time horizons: a couple of minutes (operation) to weeks or even months (planning). The approach proposed can also be applied in cases where the VPP aggregate different type or number of consumers, DG units and prosumers. Aggregators with only one type of resource will also be able to use the methodology. In the profiling, all the information regarding the resources is considered. All the information from each resource is used as input for the second step, Scheduling, based on a deterministic approach where the objective function, from the point of view of the VPP, is to minimize the operation costs.

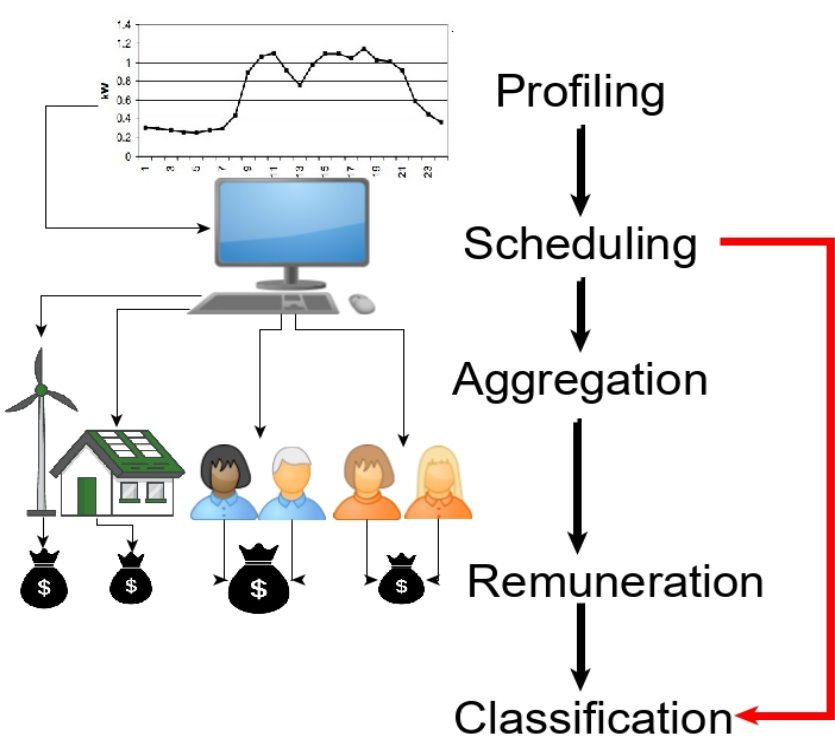

Figure 1 Proposed Methodology

It is important to highlight that through the present paper the first phase may be referred as Scheduling or Optimization phase. As already mentioned, consumers and DG units are considered for the optimization, however, for the case where the production from DG units is not enough to suppress the demand, suppliers were applied. Two types were considered: regular and additional. Let $\mathrm{p}, \mathrm{sr}$, sa and $\mathrm{c}$ be the number of $\mathrm{DG}$ units, regular suppliers, additional suppliers and consumers, respectively. The objective function is given by:

$$
\begin{aligned}
& \text { MinOF }=\sum_{p=1}^{P} P_{D G(p)} C_{D G(p)}+\sum_{s r=1}^{S t} P_{\text {Sipplier }(s r)}^{\text {reg }} C_{\text {Sipplier }(s r)}+\sum_{s a=1}^{S a} P_{\text {Sipplier }(s a)}^{\text {add }} C_{\text {Sipplier }(s a)}+ \\
& \sum_{c=1}^{C} P_{D R(c)} C_{D R(c)}+P_{N S P} C_{N S P}
\end{aligned}
$$

Power balance is modeled as in Equation (2).

$$
\begin{aligned}
& \sum_{c=1}^{C}\left[P_{\text {Load }(c)}^{\text {Initial }}-P_{D R(c)}\right]=\sum_{p=1}^{P} P_{D G(p)}+\sum_{s r=1}^{S r} P_{\text {Supplier }(s r)}^{\text {reg }}+ \\
& \sum_{s a=1}^{S a} P_{\text {Supplier }(s a)}^{\text {add }}+P_{N S P}
\end{aligned}
$$

The sum of the reduction of each IDR consumer to its initial load is equal the sum of all DG units and suppliers. The goal of an optimum network flows it to kept $\mathrm{P}_{\mathrm{NSP}}$ null, proving that the grid is being well managed.

Passing to the constraints associated with the consumers belonging to DR programs. In Equation (3), the restriction for the maximum value of reduction for all the consumers is presented.

$$
P_{I D R(c)} \leq P_{I D R(c)}^{M a x}, \forall c \in\{1, \ldots, C\}
$$

DG units are limited by Equations (4), (5) and (6). Considering Equation (4) and (5), the low and high bounds are applied to all the units. Also, it is considered a total maximum 
value of production for these technologies giving the Aggregation some control.

$$
\begin{gathered}
P_{D G(p)} \leq P_{D G(p)}^{\operatorname{Max}}, \forall p \in\{1, \ldots, P\} \\
P_{D G(p)} \geq P_{D G(p)}^{\operatorname{Min}}, \forall p \in\{1, \ldots, P\} \\
\sum_{p=1}^{P} P_{D G(p)} \leq P_{D G}^{\text {TotalMax }}
\end{gathered}
$$

The limits for external suppliers are as in Equations (7) (10). In addition to the upper limit, it is also limited the total amount of external suppliers, both regular (Equation 7 and Equation 8) or additional (Eq. 9 and Eq. 10).

$$
\begin{aligned}
& P_{\text {Supplier }(s r)}^{\text {reg }} \leq P_{\text {Supplier }(s r)}^{\text {regMAX }}, \forall \in\{1, \ldots, S r\} \\
& \sum_{s r=1}^{\text {Sr }} P_{\text {Supplier }(s r)}^{\text {reg }} \leq P_{\text {Supplier }(s r)}^{\text {regtotaL }} \\
& P_{\text {Supplier (sa) }}^{a d d} \leq P_{\text {Supplier }(\text { sa })}^{\text {addMAX }}, \forall \in\{1, \ldots, S a\} \\
& \sum_{s a=1}^{\text {Sa }} P_{\text {Supplier }(\text { sa })}^{\text {add }} \leq P_{\text {Supplier }(\text { sa })}^{\text {addTOTAL }}
\end{aligned}
$$

Giving the output from the optimization, in case of consumers the amount of reduction required, the Aggregation and Remuneration phases are introduced. The authors consider an approach where the remuneration for resources who cooperate with the VPP is fair. In this way, the idea of grouping the resources according to the participation is performed through clustering methods. The author selected kmeans to perform the stated task. The aim is to find the centroid value that represents each group. Several functions can be applied, for example, the Euclidean distance.

The resources with higher participation belong to the same group and, consequently, will be remunerated at the same tariff being this approach used as motivation the continuous participation. Another important feature of the proposed methodology is, for the input for Aggregation, the optimum number of clusters $-k_{\text {opt }}$ for the given database. Several methods can be used to perform the mentioned task [7]. The authors considered, for the present paper, Elbow Method. Starting at $\mathrm{k}=2$, with a step 1 , the total within-cluster sum of square is calculated for each $\mathrm{k}$ and then the kopt is found. An "elbow" is considered as an indicator of the suitable number of clusters. The comparison between the ideal number of clusters and the optimal was already studied in previous works [6].

Classification phase is introduced with the operation approach. Giving the data from previous planning results it is possible to have training data to design a model to be applied near real-time. The goal is, with the results from the scheduling attribute a remuneration group and tariff to a resource without going through all the phases. The authors consider, for the present paper, Decision Trees as a classification method to perform this task. As the name suggests, a tree structure to class objects is created by dividing the dataset into smaller subsets with several rules.

\section{CASE STUDY}

The case-study includes a $30 \mathrm{kV}$ Real Portuguese distribution network, $30 \mathrm{kV}, 90 \mathrm{MVA}$. The database containing consumer and DG units' profiles. This case study has a total of 548 DG units, with seven different types of technologies as showed in Table 1. This table presents some characteristics of these units, namely the value of tariffs and the total number of each type.

Table 1 Distributed Generation units' characterization

\begin{tabular}{|l|c|c|}
\hline \multicolumn{1}{|c|}{ Type } & $\begin{array}{c}\text { Tariff } \\
{[\mathbf{m . u .} / \mathbf{k W h}]}\end{array}$ & \# Units \\
\hline Biomass & 0.1206 & 25 \\
\hline Co-generation & 0.0975 & 16 \\
\hline Fuel Cell & 0.0945 & 13 \\
\hline Photovoltaic & 0.2889 & 208 \\
\hline Small Hydro & 0.0961 & 25 \\
\hline Waste-to-energy & 0.0900 & 7 \\
\hline Wind & 0.0988 & 254 \\
\hline \multicolumn{2}{|c|}{ Total } & 548 \\
\hline
\end{tabular}

Consumers, within five different, are presented in Table 2. The tariffs are divided according to a schedule, and there are

\begin{tabular}{|c|c|c|c|c|}
\hline $\begin{array}{c}\text { Type of } \\
\text { Consumer }\end{array}$ & Type of Schedule & Period & $\begin{array}{c}\text { Tariff } \\
{[\mathrm{m} . u . / \mathrm{kW}]}\end{array}$ & \# Units \\
\hline Domestic & Single $\leq 2.3 \mathrm{kVA}$ & - & 0.1426 & 10,168 \\
\hline $\begin{array}{l}\text { Small } \\
\text { Commerce }\end{array}$ & Single $\geq 2.3 \mathrm{kVA}$ & - & 0.1652 & 9828 \\
\hline \multirow{2}{*}{$\begin{array}{l}\text { Medium } \\
\text { Commerce }\end{array}$} & \multirow{2}{*}{ Double } & Off-valley & 0.1948 & \multirow{2}{*}{82} \\
\hline & & Valley & 0.1016 & \\
\hline \multirow{2}{*}{$\begin{array}{l}\text { Large } \\
\text { Commerce }\end{array}$} & \multirow{3}{*}{ Triple } & Peak & 0.2253 & \multirow[b]{2}{*}{85} \\
\hline & & Off-valley & 0.1765 & \\
\hline & & Valley & 0.1016 & 147 \\
\hline & & & Total & 20,310 \\
\hline
\end{tabular}
three types of schedules. With this, single is when the tariff is the same all day; double when the day is divided into offvalley periods and valley periods; triple when there are peak, off-peak and valley periods. Tariffs are different depending on the day of the week and season.

Table 2 Consumers' characterization

The aggregator is thus responsible for providing all the above characteristics, for each of the resources, in order to obtain viable results through this methodology. For aggregation, remuneration and classification phase, in the present paper, the focus will be on consumers.

\section{RESULTS}

The results presented in this section were obtained by comparing the proposed path in the present paper for a realtime approach - Scheduling and Classification and following all the phases from the proposed methodology. To test the viability, the introduction of five new consumers was performed. First, to create the decision tree, all phases of the proposed methodology were tested. Only one period was performed - a peak hour, for the real-time approach. Table 3 shows the characteristics from the consumers, namely, 
PinLoad which represent the initial load at the period studied and Pmaxidr the maximum amount that can be reduced according to the DR program from each consumer.

Table 3 New Consumers' Characteristics

\begin{tabular}{|c|c|c|c|c|c|}
\hline \multirow{2}{*}{ Parameter } & \multicolumn{5}{|c|}{ Consumer } \\
\cline { 2 - 6 } & 1 & 2 & 3 & 4 & 5 \\
\cline { 2 - 6 } & $\mathrm{DM}$ & $\mathrm{SC}$ & $\mathrm{MC}$ & LC & ID \\
\hline PinLoad & 5.1558 & 2.3423 & 17.6754 & 69.8520 & 113.3917 \\
\hline Pmaxidr & 2.4921 & 1.1282 & 8.8377 & 34.9260 & 56.6959 \\
\hline
\end{tabular}

One consumer from each group defined in the previous section was chosen. The Domestic Consumer (1), for the period studied, has as initial load of $5.15 \mathrm{~kW}$, having a DR program which allows the Aggregator to reduce $2.49 \mathrm{~kW}$. In the case of the Small Commerce Consumer (2), consumption is lower, and the maximum load reduction is $48 \%$ of his initial load.

Regarding Medium Commerce Consumer (3), Large Commerce Consumer (4) and Industrial Consumer (4), the maximum reduction is $50 \%$ of the initial load. With this information, and taking into account the remaining consumers in the grid as well the DG units and the suppliers, the optimization phase has been performed and the results for the selected period are represented in Table 4.

Table 4 Optimization Results

\begin{tabular}{|c|c|c|c|c|}
\hline \multicolumn{5}{|c|}{ Consumer } \\
\hline 1 & 2 & 3 & 4 & 5 \\
\hline DM & SC & MC & LC & ID \\
\hline 2.4921 & 1.1282 & 8.8377 & 34.9260 & 56.6959 \\
\hline
\end{tabular}

All the consumers were requested to reduce all the maximum value allowed for the DR program. Following, Aggregation and Remuneration phase was performed. The resulting groups were presented in Table 5 and in Table 6 the remuneration tariffs.

Table 5 Aggregation Groups

\begin{tabular}{|c|c|c|c|c|}
\hline \multicolumn{5}{|c|}{ Consumer } \\
\hline 1 & 2 & 3 & 4 & 5 \\
\hline DM & SC & MC & LC & ID \\
\hline 3 & 4 & 3 & 5 & 5 \\
\hline
\end{tabular}

Table 6 Remuneration Tariffs

\begin{tabular}{|c|c|c|c|c|}
\hline \multicolumn{5}{|c|}{ Consumer } \\
\hline 1 & 2 & 3 & 4 & 5 \\
\hline DM & SC & MC & LC & ID \\
\hline 0.1948 & 0.1652 & 0.1948 & 0.2253 & 0.2253 \\
\hline
\end{tabular}

For the formation of remuneration groups, in Aggregation phase, a selected clustering method, k-means was used. The results are present only for the one $\mathrm{k}$ cluster chosen earlier. In the remuneration phase, it was considered the method with lower costs for the VPP but maintaining the fair remuneration for the participants. The remuneration tariffs presented in Table 6 were designated through the maximum value in the remuneration group of each consumer.
In this way, for Consumer 1 the remuneration tariff was $0.1948 \mathrm{~m} . \mathrm{u} . / \mathrm{kW}$. This tariff is higher than the $0.1426 \mathrm{~m} . \mathrm{u} . / \mathrm{kW}$ accorded in the optimization phase because this Consumer is in the same group as Consumer 3, Group 3. Being the maximum per group, Consumer 1 is incentivized to continuously participate in DR programs with this higher compensation tariff. Regarding Consumer 2, the clustering method opts to attribute to Group 4 where the remuneration tariff is 0.1652 m.u. $/ \mathrm{kW}$. Consumer 4 and Consumer 5 belong to the same Group and have a higher tariff, 0.2253 m.u. $/ \mathrm{kW}$. Since the effort is higher (amount of reduction from DR programs) it is fair to remunerate this Consumer with higher values.

For Classification phase, in this planning path, a decision tree was created considering the results from the optimization and the remuneration groups (Figure 2).

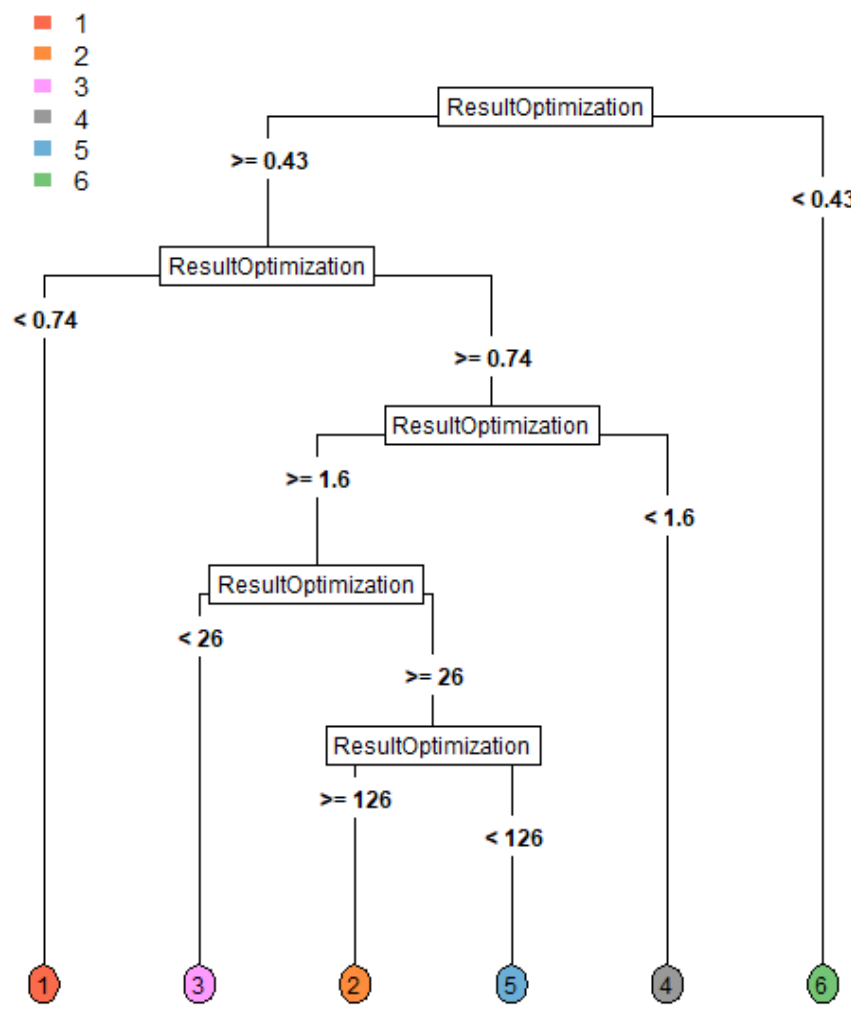

Figure 2 Resulting Decision Tree from Classification phase (planning path).

Following the second path, a real-time approach, a new optimization phase was performed and taking into account the output from it, the decision tree in Figure 2 was applied to the consumers. Proving the viability of the methodology and this new phase, the consumers should find a remuneration group with a fair remuneration considering their participation without going to all the phases. In the re-scheduling, the results for the selected consumers were the same as presented in Table 4.

Figure 3, Figure 4 and Figure 5 show the results from applying the decision tree in Figure 2 to the selected 
consumers. Each consumer's path has the colour of the assigned group: Group 1 is red, Group 2 is orange, Group 3 is pink, Group 4 is grey, Group 5 is blue, and Group 6 is green. It is essential to recall that each group has associated one remuneration tariff, being the maximum tariff in the group.

Starting with Figure 3, where it is represented the path for Consumer 1 and 3, where the results from the optimization phase were $2.4921 \mathrm{~kW}$ and $8.8377 \mathrm{~kW}$, respectively. The first division splits the Database in higher or equal to 0.43 and lower than 0.43 . Being obviously higher, follow to the second division where the Database is tested for higher or equal to 0.74 and lower than 0.74 . Following the higher path, the fourth division compares being higher or lower than 26. Now, these two consumers are between 1.6 and 26 , is assigned to Group 3.

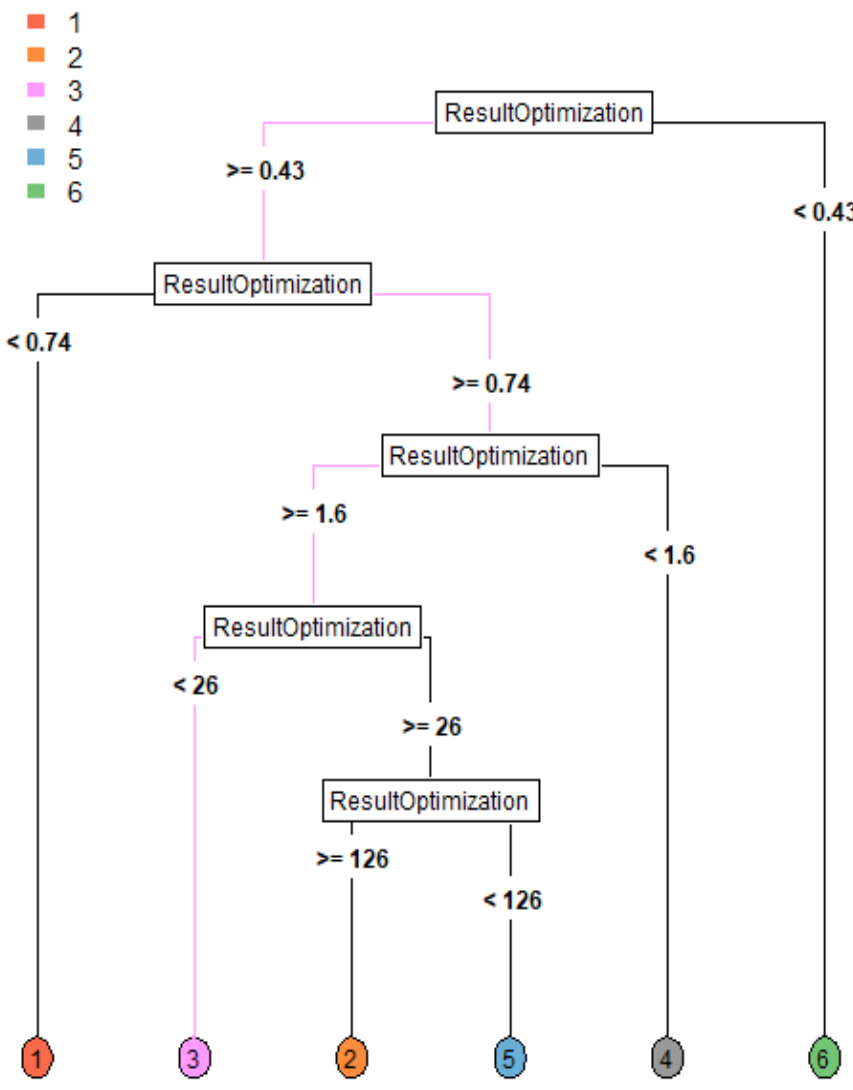

Figure 3 Decision tree results for Consumers 1 and 3

In Figure 4, the resulting path for consumer 2 is presented with grey. The optimization result for this Consumer was $1.1282 \mathrm{~kW}$. For the first test in the Decision Tree - higher or equal to 0.43 and lower, this Consumer has a higher value. In the second test, higher or equal to 0.74 and lower, remains higher than the test value. Following the second test - higher or equal to 1.6 or lower, the bounds were found. The result is higher than 0.74 but lower than 1.6, staying in the remuneration Group 4.

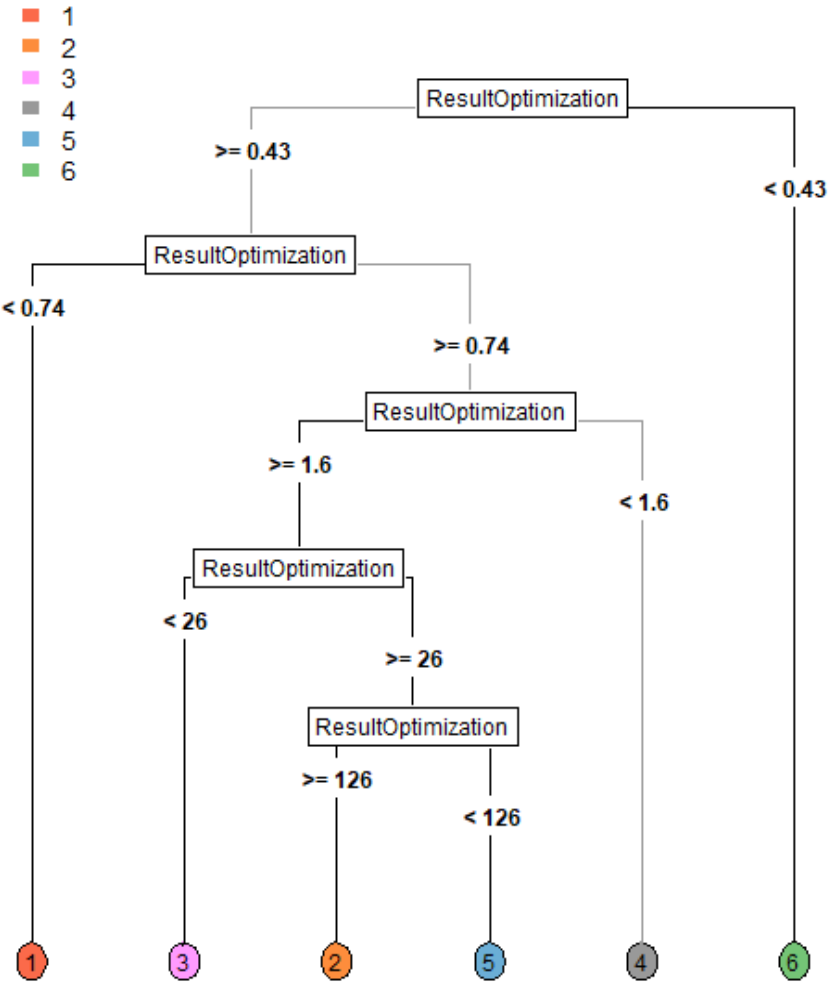

Figure 4 Decision tree results for Consumers 2

Figure 5 shows the remaining consumers.

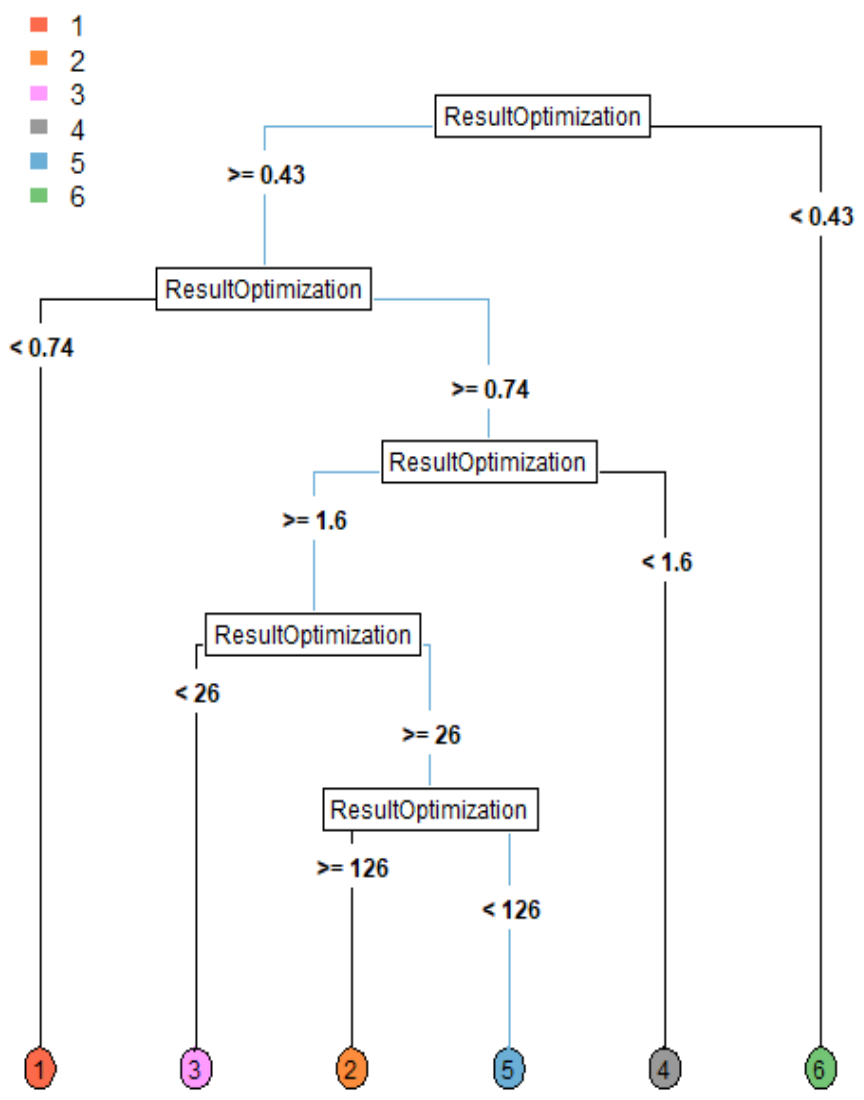

Figure 5 Decision tree results for Consumers 4 and 5 
These are Consumer 4 and Consumer 5 where the results from the scheduling were $34.9260 \mathrm{~kW}$ and 56.6959 $\mathrm{kW}$. In this way, these values are higher than 0.43 (first test), higher than 0.74 (second test), higher than 1.6 (third test) and higher than 26 (fourth test). The upper bound is found with the fifth test, where is compared if the value is higher or equal to 126 or lower. The results for Consumer 4 and 5 are lower, and, with this, they belong to remuneration group 5, represented with a blue path.

\section{Conclusions}

Considering the lack of business models with small resources, namely small consumers belonging to DR programs and small DG units, the authors proposed a methodology that will help the Aggregator minimize the operation costs and still remunerate fairly all the participants in the management of the local community. In the present paper, a study was done comparing two approaches: planning and real-time. These two have different paths through the phases of the proposed methodology.

The main goal was to understand and prove the viability of the operation approach. Studying 5 different consumers and comparing the results for the two approaches, it is proved that, with the decision tree created, the consumers ended in the same group as planning approach (with more historical data). With this, following the alternative path, when lacks time for the Aggregator to perform all the methodology phases, this can be a good substitute. It is highlighted the importance of having a good training database to form the rules in the Decision Tree, is crucial to obtain good results.

\section{REFERENCES}

[1] J. Zupancic et al., "Market-based business model for flexible energy aggregators in distribution networks," Int. Conf. Eur. Energy Mark. EEM, 2017.

[2] J. Villar, R. Bessa, and M. Matos, "Flexibility products and markets: Literature review," Electric Power Systems Research, vol. 154. Elsevier, pp. 329-340, 01-Jan-2018.

[3] V. Rious, Y. Perez, and F. Roques, "Which electricity market design to encourage the development of demand response?," Econ. Anal. Policy, vol. 48, pp. 128-138, Dec. 2015.

[4] P. Faria, J. Spínola, and Z. Vale, "Aggregation and Remuneration of Electricity Consumers and Producers for the Definition of Demand-Response Programs," IEEE Trans. Ind. Informatics, vol. 12, no. 3, pp. 952-961, Jun. 2016.

[5] C. Silva, P. Faria, and Z. Vale, "Discussing Different Clustering Methods for the Aggregation of Demand Response and Distributed Generation," in 2018 IEEE Symposium Series on Computational Intelligence (SSCI), 2018.

[6] C. Silva, P. Faria, and Z. Vale, "Multi-Period Observation Clustering for Tariff Definition in a Weekly Basis Remuneration of Demand Response," Energies, vol. 12, no. 7, p. 1248, 2019.

[7] B. Purnima and K. Arvind, "EBK-Means: A Clustering Technique based on Elbow Method and K-Means in WSN," Int. J. Comput. Appl., vol. 105, no. 9, pp. 17-24, 2014. 